\title{
THE NAILBED CAPILLARIES IN DISSEMINATED SCLEROSIS
}

BY

\author{
J. H. D. MILLAR and D. G. F. HARRIMAN \\ From the Department of N'eurology, Royal Victoria Hospital, Belfast
}

The object of this investigation was to compare the shape of the capillaries of the nailbed in 31 cases of disseminated sclerosis with those of 34 controls.

Gomirato (1939), reported that an abnormality was present in $80 \%$ of 12 cases of disseminated sclerosis in the capillaries of the nailbed. These abnormalities consisted of dilatation, tortuosity, and spiral formation of the loops. Chiavacci and Putnam (1949), studied 48 patients and nine controls and stated that almost all of the 48 cases of disseminated sclerosis showed an abnormality, but that this abnormality did not correspond with the severity of the patient's clinical picture. They stressed thickening of the intermediate portion of the loop, spasticity and narrowness, usually on the arterial side, and sluggishness or absence of circulation in the capillary loops.

It seemed important, therefore, to substantiate these claims in view of the conflicting evidence in the literature concerning the possibility of an underJying vascular factor in the aetiology of the disease (Putnam, 1937 ; Dow and Berglund, 1942).

Krogh (1922) and Callander (1925), among many, have emphasized the variation in number, shape, and size of the nailbed capillaries in healthy persons and stated how difficult it would be to draw any conclusions concerning alterations in pattern in disease. The number of loops seen at one time depends on the blood flow through the hand, and this varies considerably under standard conditions (Cooper, Cross, Greenfield, Hamilton, and Scarborough, 1949). For example, the capillaries may disappear from view owing, possibly, to a shunt at the glomus. The rate of flow probably depends to some extent on the degree of this shunt so that no comparisons can be made on the number of capillaries or the rate of flow seen at any one time.

Crawford and Rosenberger (1926) studied the nailbed capillaries of eight normal individuals by means of cinematography over a period of days. Changes took place from moment to moment and from day to day. These changes were relatively small compared with the total breadth of the arterial or venous limbs which remained approximately the same from day to day. From these findings it is therefore justifiable to draw conclusions only from the shape and size of the loops and not from the rate of flow. Also one observation is sufficient if made under uniform conditions.

\section{Method}

The patients and controls were examined under room conditions, seated comfortably in a chair. The control group consisted of healthy laboratory assistants, nurses, medical students, and young doctors. The fingers of both hands, most often the ring finger, were examined with a Zeiss skin and capillary microscope (Type 4); four or five photographs were taken in each case. Negatives were taken on standard orthochromatic film,

TABLE

DISTRIBUTION OF CAPILLARY LOOP PATTERNS IN THE TWO SERIES

\begin{tabular}{|c|c|c|c|c|c|c|c|}
\hline $\begin{array}{c}\text { Capillary Loop } \\
\text { Patterns }\end{array}$ & & $\begin{array}{c}\text { Straight } \\
\text { Limbs }\end{array}$ & $\begin{array}{c}\text { Spiral } \\
\text { Formations }\end{array}$ & $\begin{array}{c}\text { One } \\
\text { Limb } \\
\text { Thicker }\end{array}$ & $\begin{array}{l}\text { Thick } \\
\text { Arch }\end{array}$ & $\begin{array}{l}\text { Mixed } \\
\text { Types }\end{array}$ & Total \\
\hline Disseminated sclerosis & .. & 11 & 8 & 4 & 4 & 4 & 31 \\
\hline Cont rol group & .. & 11 & 10 & 6 & 2 & 5 & 34 \\
\hline
\end{tabular}


D.S.

Controls

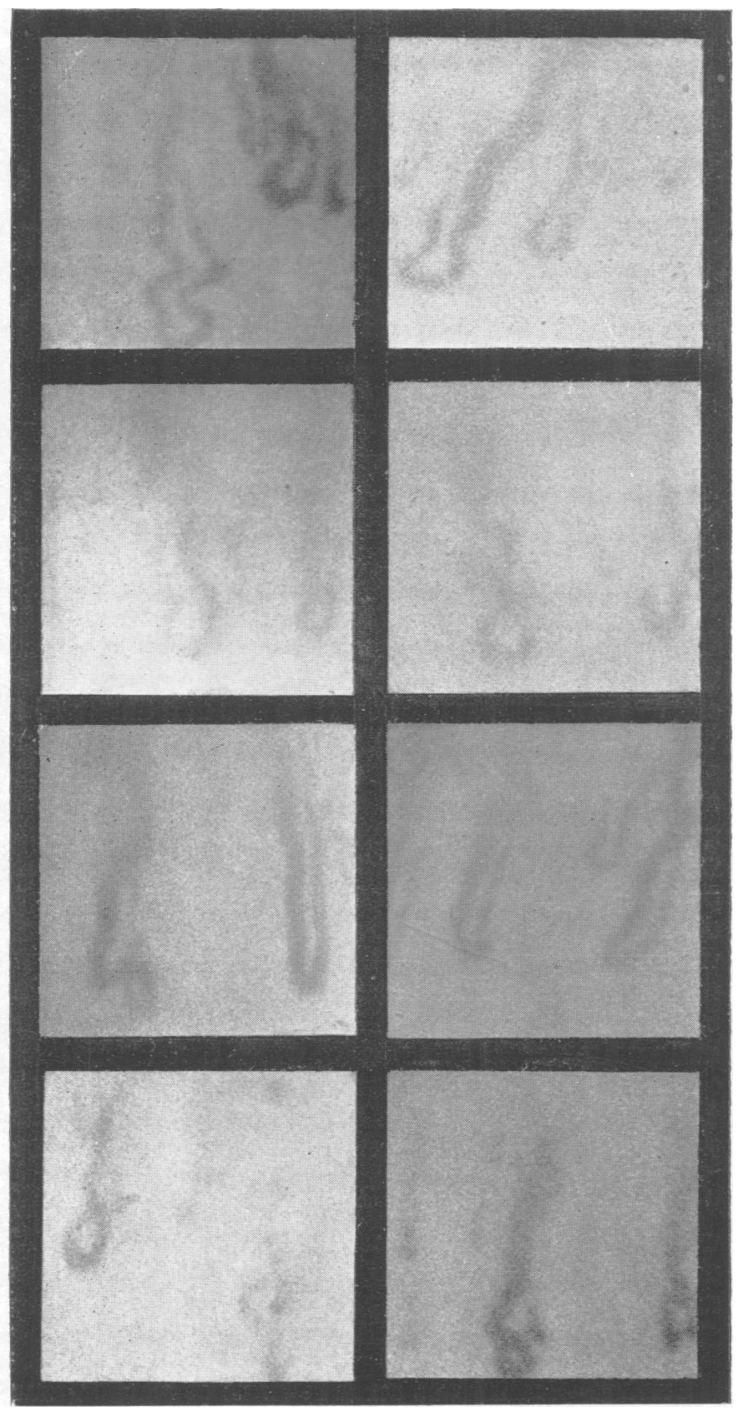

FIG. 1.-Samples of the photographs obtained in both series to emphasize the variability of the patterns.

without a filter; the picture size was $1 \frac{5}{3} \times 1 \frac{1}{4}$ in. Standard magnification was employed in enlargement on to the paper available giving the greatest contrast. None of the photographs are retouched. Direct photography was held to be more satisfactory than camera lucida drawings.

\section{Results}

As the normal pattern was not familiar to us, it was decided to start with an examination of the controls, and later proceed to the established cases of disseminated sclerosis. As the controls were examined it became increasingly apparent that there were wide variations in shape and size of the capillaries ; some had thickened limbs, others were spirally formed, and in many cases there was a lack of uniformity in the appearance of the capillaries, even in the same nailbed. In the middle stages of the investigation controls and patients were frequently examined in sequence. Direct comparisons were therefore possible and we gained the impression that there was no difference between disseminated sclerosis cases and controls. To obviate prejudice however, all the photographs, both of patients and controls, were shown to several neutral observers, without indicating to them which were patients and which controls. The photographs were examined by sorting into similar shapes and sizes, but no one could find any significant pattern for the patients. All observers were struck by the variations (Fig. 1) in shape and size which occurred in the capillaries of both series.

An arbitrary division into five groups was made of the capillary loops; (i) with straight limbs, (ii) with spiral formations, (iii) with one thicker limb, (iv) with a thickened arch, and (v) mixed types. As can be seen from the table, no distinction can be made between the appearances seen in disseminated sclerosis and in the control series.

\section{Summary}

The nailbeds of 31 patients suffering from disseminated sclerosis were studied and compared with 34 normal controls. No significant difference could be seen in the size and shapes of the capillary loops between the two series.

We wish to thank Dr. R. S. Allison for his encouragement ; Professor A. D. H. Greenfield and assistants of the Department of Physiology, Queen's University, Belfast, who examined and compared the photographs ; and Professor J. H. Biggart, Director, Department of Pathology, Queen's University, Belfast, for the use of the capillary microscope.

\section{REFERENCES}

Callander, C. L. (1925). J. Amer. med. Ass., 84, 352.

Chiavacci, L. V., and Putnam, T. J. (1949). Arch. Neurol. Psychiat., Chicago, 61, 577.

Cooper, K. E., Cross, K. W., Greenfield, A. D. M., Hamilton, D. McK., and Scarborough, H. (1949). Clin. Sci., 8, 217.

Crawford, J. H., and Rosenberger, H. (1926). J. clin. Invest., 2, 351.

Dow, R. S., and Barglund, G. (1942) Arch. Neurol. Psychiat., Chicago, 47, L

Gomirato, G. (1939). Riv. Pat. nerv. ment., 53, 148.

Krogh, A. (1922). "Anatomy and Physiology of Capillaries", pp. 170-171. Yale Univ. Press.

Putnam, T. J. (1937). Arch. Neurol. Psychiat., Chicago, $37,1298$. 